Research Article

\title{
Chloride Penetration in Lightweight Aggregate Mortars Incorporating Supplementary Cementing Materials
}

\author{
Maria Stratoura $\mathbb{D},{ }^{1,2}$ Diana-Ruxandra $\operatorname{Iaz}\left(\mathbb{D},{ }^{3}\right.$ and Efstratios Badogiannis $\mathbb{D}^{2}$ \\ ${ }^{1}$ Department of Environmental and Natural Resources Management, University of Patras, Patras, Greece \\ ${ }^{2}$ School of Civil Engineering, National Technical University of Athens, Athens, Greece \\ ${ }^{3}$ School of Civil Engineering, Technical University of Cluj-Napoca, Cluj-Napoca, Romania
}

Correspondence should be addressed to Efstratios Badogiannis; badstrat@central.ntua.gr

Received 31 March 2018; Accepted 3 June 2018; Published 3 July 2018

Academic Editor: Damien Rangeard

Copyright (c) 2018 Maria Stratoura et al. This is an open access article distributed under the Creative Commons Attribution License, which permits unrestricted use, distribution, and reproduction in any medium, provided the original work is properly cited.

\begin{abstract}
The current research is aiming to investigate the chlorides' penetration resistance of 9 different pumice lightweight aggregate mortars (LWAMs). The composition of the mixture is altered by the addition of metakaolin, fly ash, silica fume, and ground granulated blast furnace slag, substituting $10 \%$ and $20 \%$ of cement by mass. Workability and compressive strength of the mortars are studied together with durability parameters like water absorption due to capillary absorption and porosity. Moreover, the mortar resistance to chloride penetration is evaluated through non-steady-state chloride migration coefficient, complying to NT BUILD 492 standard. Summarizing all the laboratory test results, while the addition of metakaolin in the range of $20 \%$ led to better workability, higher compressive strength, lower sorptivity, and lower volume of open porosity, it did not improve the resistance against chlorides' penetration.
\end{abstract}

\section{Introduction}

Concrete is the world's most used construction material. Current estimates put global concrete production at around $10 \mathrm{~km}^{3}$ per year, and this number continues to increase due to massive urban and national infrastructure development all over the world [1]. Because of the sheer volume of concrete used and the associated resources and energy required to produce it, the wise use of this material can significantly contribute in achieving rational development. Many aspects of sustainability are inherent in concrete industry, such as durability/longevity, economy, local impact, and thermal advantages. Therefore, in order for engineers to find out answers to the question "What defines a successful building for sustainable development?", a thorough looking at the entire life cycle of a concrete structure should focus on areas where changes will make the most impact [2].

The application of lightweight aggregates in concrete technology meets 3 of the 4 above-mentioned aspects of concrete structures' sustainability. Their use has lower local environmental impact since lightweight aggregates are often made from industrial by-products (i.e., fly ash aggregates). On the other hand, natural resources, such as pumice, perlite, or scoria, could also be used instead of the conventional limestone aggregates, increasing the economical impact that the exploitation of additional natural resources offers [3-7]. Finally, lightweight aggregates provide lower coefficient of thermal expansion and superior heat and sound insulation characteristics in the lightweight aggregate concrete (LWAC), due to their inner air voids [8-11].

Since it is well known that there are practical and technical benefits of using lightweight aggregate concrete, it has been successfully investigated for structural purposes, for many years [12]. Lightweight concrete weights typically $25 \%$ to $35 \%$ less than normal-weight concrete, but its strength is comparable to normal-weight concrete. Thus, higher strength-to-weight ratio, better tensile strain capacity, and lower density, which reduce dead loads in construction, are the main benefits from its use of LWAC [13-16].

Pumice is the most widely used natural lightweight aggregate [17]. It is a natural material of volcanic origin produced by the release of gases during the solidification of 
lava [18]. Because of its physical, chemical, and mechanical properties, pumice is a well-known lightweight concrete aggregate for over 2000 years $[19,20]$. The connectivity of its pore structure may range from completely closed to completely opened. Pores ranging from hundreds of microns to a few microns are visible. The pores appear irregular in shape and well connected [17].

Durability is certainly considered, the fourth aspect of concrete sustainability. It has been thoroughly studied by many researchers [21-23] where among other durability parameters, chloride penetration resistance is assessed as one of the most important ones [24-27]. There are many test methods that evaluate the resistance of concrete to chloride ion penetration; each one of them has advantages and disadvantages. The rapid chloride permeability test (RCPT) is increasingly being used because of its simplicity. However, several researchers have raised concerns over this test. The RCPT is an index test in which no steady state conditions exist. The RCPT is a useful comparative indicator in assessing the relative resistance of different concrete mixtures to chloride ion penetration $[28,29]$. The RCPT measures the conductivity of all ions in the pore solution, which includes $\mathrm{OH}^{-}, \mathrm{Cl}^{-}, \mathrm{Na}^{+}, \mathrm{K}^{+}, \mathrm{SO}_{4}{ }^{2+}$, and $\mathrm{Ca}^{2+}$, whose concentrations vary for different concretes, due to the cement type or the usage of different supplementary cementing materials (SCMs) [30, 31]. The replacement of Portland cement with SCMs, such as silica fume or fly ash, can reduce the electrical conductivity of concrete by more than $90 \%$ due to the change in the chemical composition of the pore solution, which has little to do with the transport of chloride ions in concrete $[28,31]$, arguing that RCPT does not directly measure the true permeability but instead measures concrete resistivity. Shi et al. [31] stated that replacement of cement with silica fume can result in an order of magnitude reduction in $\mathrm{Na}^{+}, \mathrm{K}^{+}$, and $\mathrm{OH}^{-}$concentrations. On the other hand, fly ash might either increase or decrease $\mathrm{Na}^{+}$and $\mathrm{K}^{+}$ ions and usually decreases $\mathrm{Ca}^{2+}$ and $\mathrm{OH}^{-}$concentrations in the pore solution. The presence of slag increases $\mathrm{Na}^{+}$concentration in the pore solution but decreases $\mathrm{K}^{+}$, despite the fact that slag usually lacks sodium.

However, little research has been done on the durability of LWAC with mineral admixtures, not to mention the combination of several types of mineral admixtures $[12,32,33]$. Hence, in this study, the effect of the addition of SCMs such as metakaolin, fly ash, granulated blast furnace slag, and silica fume on the durability of lightweight aggregate mortars is examined. Chloride penetration resistance, together with other durability parameters, such as open porosity and sorptivity, is studied.

\section{Materials and Mixtures}

Nine different mixtures of lightweight mortars were produced. They contain pumice as a lightweight fine aggregate (sand) of $0-2 \mathrm{~mm}$ grain size and four SCMs, metakaolin (MK), fly ash (FA), granulated blast furnace slag (GS), and silica fume (SF), in two cement replacing levels (10 and 20\% w/w). A typical Portland composite ASTM C-150 type I/II cement (c) was also used. The chemical composition of all
TABLE 1: Chemical analysis (\% w/w) of constituent materials.

\begin{tabular}{lcccccc}
\hline Component & Cement & Pumice & K & FA & GS & SF \\
\hline $\mathrm{SiO}_{2}$ & 20.00 & 68.58 & 47.85 & 46.96 & 54.41 & 96.40 \\
$\mathrm{Al}_{2} \mathrm{O}_{3}$ & 4.90 & 11.89 & 38.20 & 21.00 & 43.94 & 0.75 \\
$\mathrm{Fe}_{2} \mathrm{O}_{3}$ & 3.50 & 1.16 & 1.29 & 9.83 & 0.89 & 0.56 \\
$\mathrm{CaO}$ & 62.00 & 4.11 & 0.03 & 13.74 & 0.37 & 0.35 \\
$\mathrm{MgO}$ & 3.10 & 0.44 & 0.04 & 2.20 & 6.75 & - \\
$\mathrm{K}_{2} \mathrm{O}$ & 0.50 & 4.02 & - & 1.36 & 0.30 & 0.43 \\
$\mathrm{Na}_{2} \mathrm{O}$ & 0.20 & 2.77 & - & 0.16 & - & 0.04 \\
$\mathrm{SO}_{3}$ & 2.70 & - & - & 2.42 & 0.49 & 0.05 \\
$\mathrm{TiO}_{2}$ & - & 0.12 & - & - & - & - \\
$\mathrm{P}_{2} \mathrm{O}_{5}$ & - & 0.03 & - & - & - & - \\
$\mathrm{AP}$ & - & 7.41 & - & - & - & - \\
L.O.I. & 2.80 & - & 12.30 & 1.94 & 0.16 & 3.01 \\
\hline
\end{tabular}

constituent materials, used in this study, is summarized in Table 1. The mineralogical composition of pumice and SCM is presented in Figures 1 and 2, respectively. Pumice is mainly an amorphous mineral, which also contains potassium feldspar (sanidine) and quartz. Metakaolin, produced from commercial (by Imerys Minerals) kaolin (K), is also mainly amorphous and contains detectable amounts of illite and quartz (Figure 2). The fly ash used which comes from the power station of Megalopolis (Greece) can be classified as Type F according to ASTM C 618, since the sum of the oxides $\mathrm{SiO}_{2}+\mathrm{Al}_{2} \mathrm{O}_{3}+\mathrm{Fe}_{2} \mathrm{O}_{3}$ is greater than $70 \%$. FA contains quartz, feldspars, anhydrite, maghemite, gehlenite, cristobalite, zeolites, and carbonates. The granulated blast furnace slag is of Italian origin, mainly an amorphous mineral, which also contains calcite. Silica fume is a commercial product (Sika Fume HR), and it is totally amorphous. Finally, the characteristic grain size values of the used SCM are summarized in Table 2, while the specific surface of cement particles is $0.40 \mathrm{~m}^{2} / \mathrm{g}$.

The mixing proportions of all mortar mixtures are summarized in Table 3. SCMs were added in the mixtures replacing cement at two different levels, $10 \%$ and $20 \%$ by mass. The water-to-binder ratio (w/b) was kept constant at 0.55 , and superplasticizer (Sika Viscocrete) was used, in order to control the workability of the lightweight mortars. Cubic specimens of $50 \mathrm{~mm}$ side and cylindrical specimens of $100 \mathrm{~mm}$ diameter and $200 \mathrm{~mm}$ height were casted. After 1 day of moist curing, the specimens were water cured at $23 \pm 1^{\circ} \mathrm{C}$ for 28 days.

\section{Test Methods}

The mini-slump test on the 9 types of pumice LWAM mixtures was conducted in order to evaluate the rheological properties [34]. Compressive strength tests (uniaxial compression) were performed on cubic specimens, after 2, 7, 14, 28 , and 90 days of water curing. For each age, three specimens were tested, and the mean value of these measurements is reported.

The durability of the LCW mixtures was evaluated on the basis of water absorption (open porosity and capillary absorption) and chloride ion penetration resistance, on specimens cured for 28 days. The open porosity ( $p, \%)$ was 


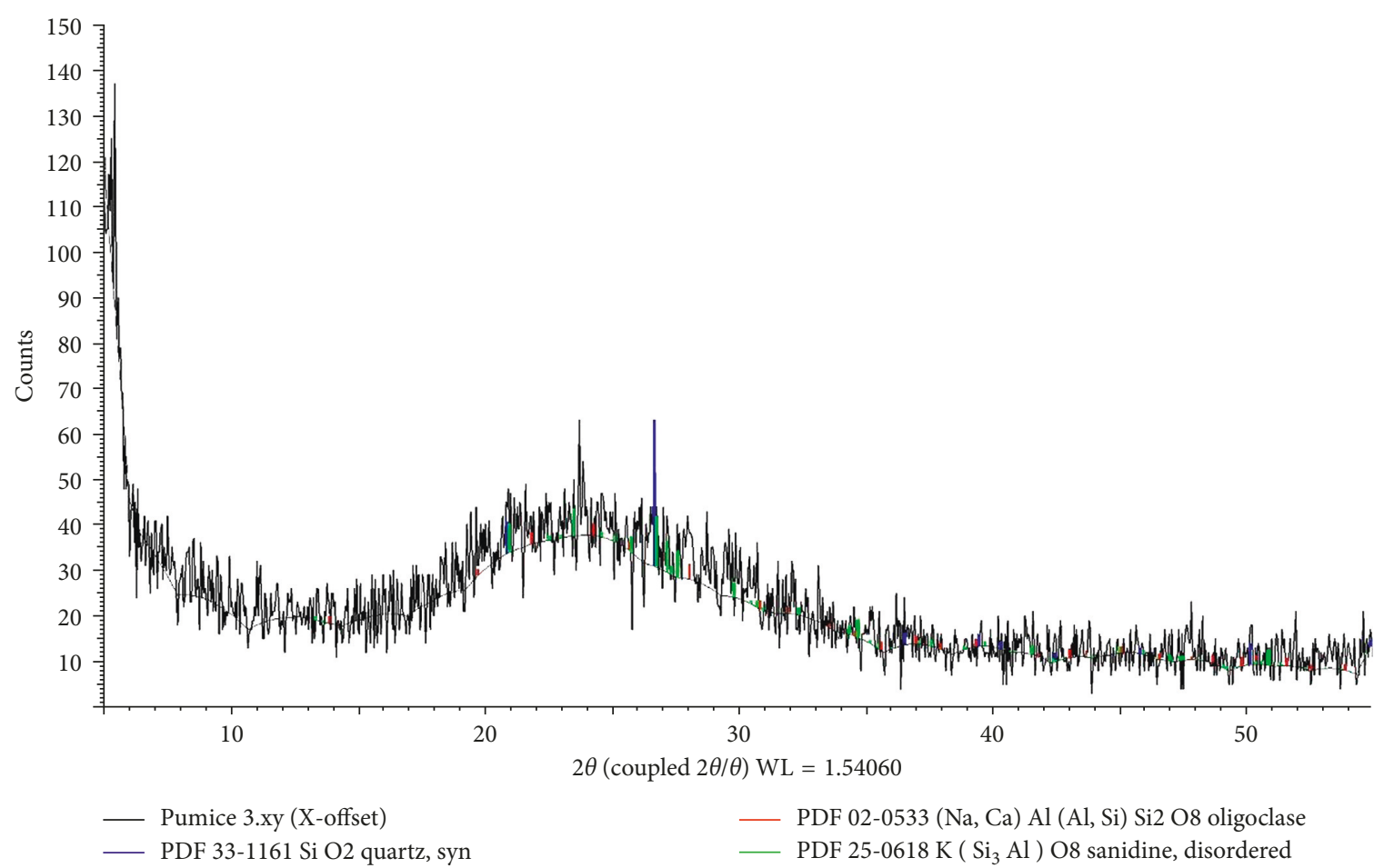

FIgURE 1: XRD pattern of pumice.

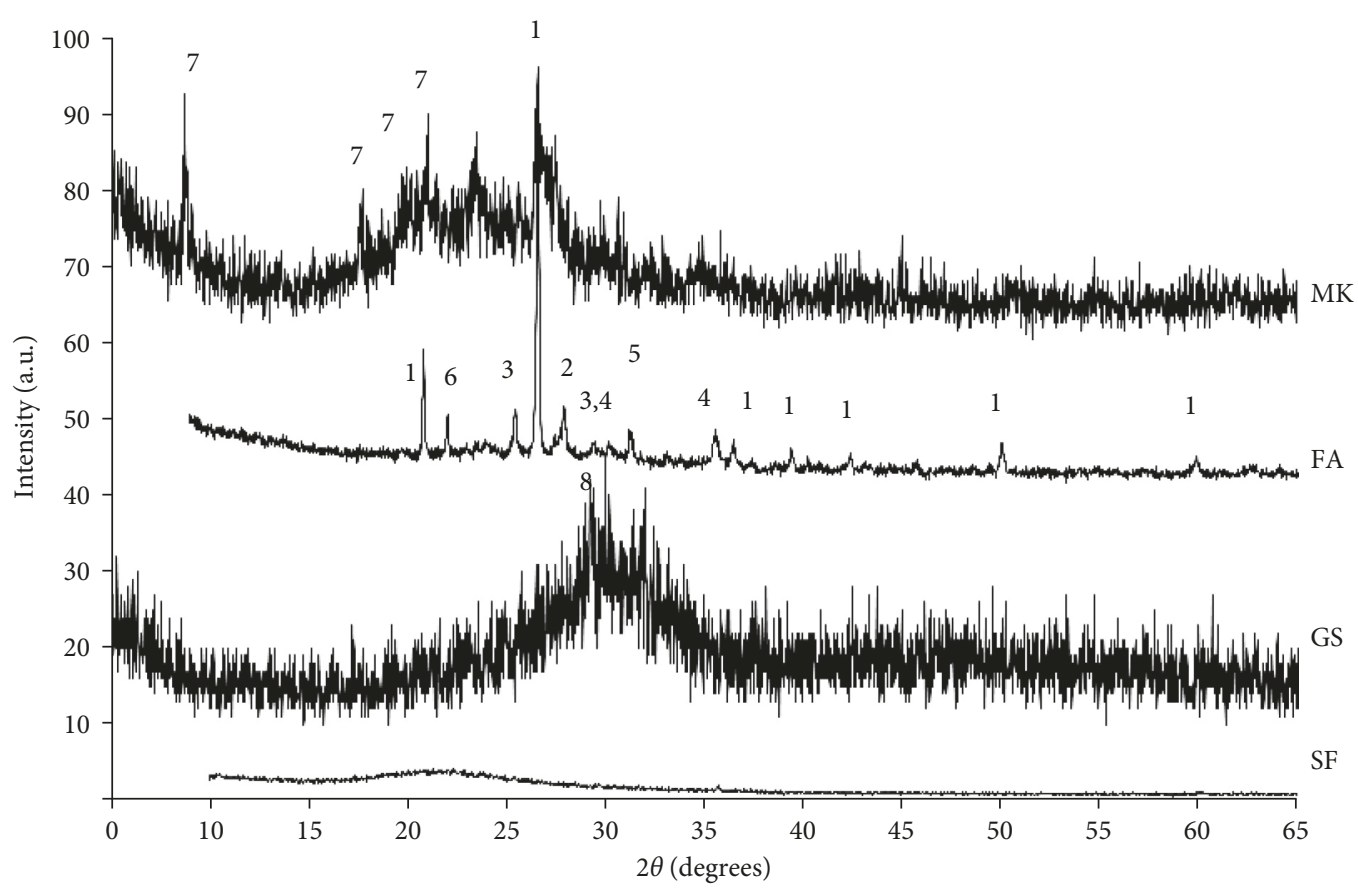

FIGURE 2: XRD patterns of all supplementary cementing materials (1: quartz, 2: feldspars, 3: anhydrite, 4: maghemite, 5: gehlenite, 6: cristobalite, 7: illite, and 8: calcite).

determined according to the American Standard ASTM C 642 [35] where the specimens are weighted, fully immersed in water, in a saturated surface dry condition, and ovendried (at $105^{\circ} \mathrm{C}$ until constant mass).

A precise procedure for the measurement of sorptivity $(S)$ has been followed as it is described by [36]. The sorptivity test was applied to a mortar cylinder of $100 \mathrm{~mm}$ diameter
TABLE 2: Characteristic values of the grain size analysis of the SCM.

\begin{tabular}{lccc}
\hline SCM & $d_{10}(\mu \mathrm{m})$ & $d_{50}(\mu \mathrm{m})$ & $d_{90}(\mu \mathrm{m})$ \\
\hline Metakaolin & 0.95 & 5.10 & 12.93 \\
Silica fume & 0.07 & 0.15 & 0.34 \\
Fly ash & 2.03 & 19.24 & 63.45 \\
GS & 2.09 & 24.17 & 74.08 \\
\hline
\end{tabular}


TABle 3: Mortars' mix design.

\begin{tabular}{lccccccccc}
\hline Materials (g) & OPC & MK 10 & MK20 & FA10 & FA20 & GS10 & GS20 & SF10 & SF20 \\
\hline Cement & 1799 & 1619 & 1439 & 1619 & 1439 & 1619 & 1439 & 1619 & 1439 \\
Pumice sand & 3334 & 3334 & 3334 & 3334 & 3334 & 3334 & 3334 & 3334 & 3334 \\
Metakaolin & - & 180 & 360 & - & - & - & - & - & - \\
Fly ash & - & - & - & 180 & 360 & - & - & - \\
Slag & - & - & - & - & - & 180 & - & - \\
Silica fume & - & - & - & - & - & - & - & 180 & 360 \\
Superplasticizer & 9.00 & 11.27 & 22.79 & 12.65 & 25.90 & 10.45 & 24.40 & 24.08 & 41.83 \\
Water-to-binder $^{1}$ & 0.55 & 0.55 & 0.55 & 0.55 & 0.55 & 0.55 & 0.55 & 0.55 & 0.55 \\
Water-to-cement & 0.55 & 0.50 & 0.44 & 0.50 & 0.44 & 0.50 & 0.44 & 0.50 & 0.44 \\
\hline
\end{tabular}

${ }^{1}$ Binder refers to the sum of all cementing materials, for instance, cement plus MK.

TABLe 4: Mini-slump test and compressive strength results of each mortar mixture.

\begin{tabular}{lccccc}
\hline \multirow{2}{*}{ Mortar mix code } & Mini-slump test $(\mathrm{cm})$ & \multicolumn{3}{c}{ Compressive strength $(\mathrm{MPa})$} \\
& & $2 \mathrm{~d}$ & $7 \mathrm{~d}$ & $\mathrm{14}$ & $28 \mathrm{~d}$ \\
\hline OPC & 19.8 & 15.67 & 19.66 & 21.45 & 31.74 \\
MK10 & 17.5 & 17.81 & 25.44 & 31.98 & 36.84 \\
MK20 & 18.9 & 20.21 & 34.34 & 41.32 & 47.69 \\
FA10 & 19.3 & 16.09 & 23.23 & 29.06 & 33.63 \\
FA20 & 20.3 & 14.52 & 21.65 & 31.06 & 34.46 \\
GS10 & 19.3 & 13.64 & 20.08 & 27.66 & 32.04 \\
GS20 & 21.0 & 16.43 & 22.77 & 27.32 & 46.23 \\
SF10 & 21.0 & 14.77 & 22.82 & 26.97 & 49.06 \\
SF20 & 20.5 & 12.36 & 25.94 & 32.86 & 35.72 \\
\hline
\end{tabular}

and $50 \mathrm{~mm}$ height. The weight changed due to the water uptake (capillary absorption). After mass stabilization, the specimens were sealed by a waterproof tape on their lateral surfaces only, in order to ensure uniaxial water absorption. The specimen was rested on rods to allow free access of water to the surface, and the tap water level was kept no more than $3 \mathrm{~mm}$ above the base of the specimen. The specimens from each mixture were tested at the age of 28 days [37].

The chloride penetration was estimated by calculating the chloride penetration coefficient, $D_{\text {nssm }}\left(\times 10^{-12} \mathrm{~m}^{2} / \mathrm{s}\right)$, using a well-established non-steady-state penetration experiment [38]. A $50 \mathrm{~mm}$ thick segment, extracted from the middle zone of a cylindrical specimen, was maintained for $24 \mathrm{~h}$ under a potential difference, between a cathode solution of $10 \%$ sodium chloride $(\mathrm{NaCl})$ by mass and an anode solution of sodium hydroxide $(\mathrm{NaOH}), 0.3 \mathrm{~N}$. It should be noted that the specimens were not dried and preconditioned in a vacuum container, as suggested by the test method, due to equipment limitations. However, given that all specimens of the present study have received the same pretreatment, that is, full saturation until the age of testing, the relative effect of chloride penetration is expected to be comparable.

At this point, it is worth mentioning that the aim of the vacuum saturation with a carbon hydroxide solution, $\mathrm{Ca}(\mathrm{OH})_{2}$, is to achieve an even ion distribution within the pore solution and thus to ensure a uniform chloride penetration throughout the specimen. However, many researchers $[39,40]$ have questioned the effectiveness of this preconditioning method, mainly due to the effect of the predrying process on the porosity. Further targeted research, investigating the effect of different preconditioning methods on the resulting chloride penetrability, would be valuable [25].

After the test completion, the determination of the chloride penetration depth was performed by a colorimetric method [40-42]. Specifically, the tested specimen was axially split into two pieces, and one of the two fractured surfaces was sprayed with a $0.1 \mathrm{M}$ silver nitrate $\left(\mathrm{AgNO}_{3}\right)$ solution. The average depth of chloride penetration was determined from the colour change in the area where the presence of chlorides chemically leads to the formation of silver chloride (AgCl). The coefficient $D_{\text {nssm }}$ was further calculated in accordance with NordTest Build 492 method [38].

\section{Results and Discussion}

Table 4 presents the experimental results for the mini-slump and compressive strength tests, and Table 5 presents open porosity $(p)$, sorptivity $(S)$, and chloride penetration coefficient $\left(D_{\text {nssm }}\right)$ values. As far as the workability of the mortars is concerned, it can be observed that the addition of SCM naturally affects the slump of the mortars, since after the addition of SCM, additional amount of pce is necessary in order to retain the initial slump of the OPC mortar. However, the consumption of pce is relatively low in the case of $10 \%$ SCM addition, with the only exception of the SF mixture, while for $20 \%$ cement replacing level, more than double of the pce amount is consumed for every SCM mixture. In any case, the workability of the mortars is effectively corrected using the suitable amount of pce (Table 3). 
TABLE 5: Open porosity $(p)$, sorptivity $(S)$, and chloride penetration coefficient $\left(D_{\text {nssm }}\right)$ results, and their variance from their counterpart values of OPC (Vopc).

\begin{tabular}{|c|c|c|c|c|c|c|}
\hline & $p(\%)$ & Vopc (\%) & $S\left(\mathrm{~mm} / \mathrm{min}^{0.5}\right)$ & Vopc (\%) & $D_{\mathrm{nssm}}\left(\times 10^{-12}\right)\left(\mathrm{m}^{2} / \mathrm{s}\right)$ & Vopc (\%) \\
\hline OPC & 33.04 & - & 0.249 & - & 11.3 & - \\
\hline MK10 & 28.95 & -12 & 0.137 & -45 & 3.0 & -74 \\
\hline MK20 & 27.29 & -17 & 0.147 & -41 & 3.9 & -66 \\
\hline FA10 & 29.59 & -10 & 0.192 & -23 & 2.3 & -80 \\
\hline FA20 & 30.69 & -7 & 0.156 & -37 & 1.3 & -88 \\
\hline GS10 & 30.87 & -7 & 0.211 & -15 & 2.4 & -79 \\
\hline GS20 & 31.61 & -4 & 0.167 & -33 & 1.5 & -87 \\
\hline SF10 & 30.55 & -8 & 0.147 & -41 & 1.8 & -84 \\
\hline SF20 & 30.53 & -8 & 0.145 & -42 & 0.9 & -92 \\
\hline
\end{tabular}

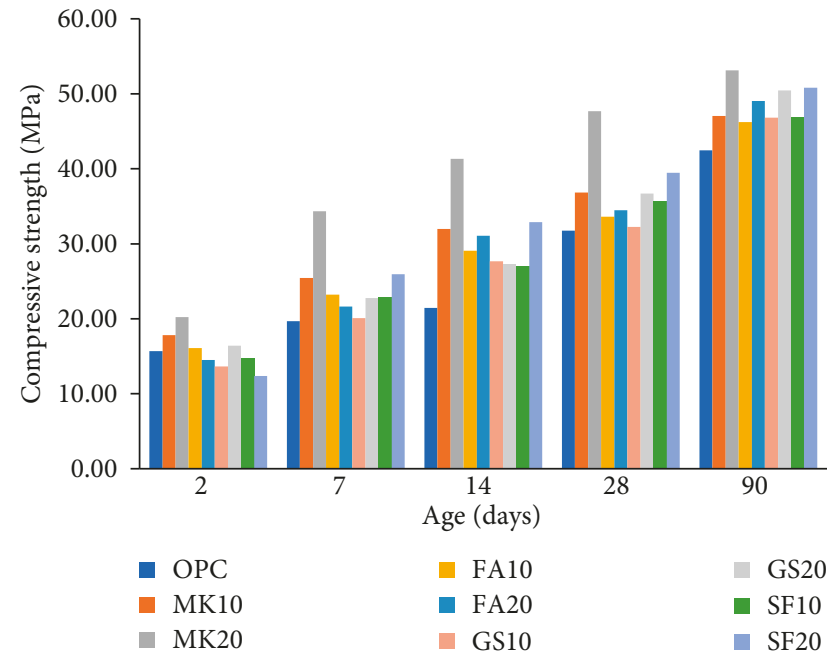

FIGURE 3: Compressive strength results of mortars containing SCM, at different curing dates.

Compressive strength values of the mortar mixtures at 2, $7,14,28$, and 90 days are illustrated in Figure 3. From the test results obtained in this research, it can be easily noticed that MK 20 exhibits the maximum values. As far as the SF is concerned, even though at the age of 2 days, the SF 20 had the lowest strength, and at 90 days, it had the second best strength, after MK 20. At the age of 7 days, the strength recorded for MK 10 and SF 20 was similar, but it can be observed that the strength gain over the time of SF 20 is greater than that of MK 10 (57\%, to $45 \%$ resp., at 28 days). Comparing to other admixtures, the two specimens with different percent of metakaolin had a constant increase. The value of MK 10 comparing to MK 20 is lower but still top third in the experimental results after 28 days. After 90 days, the strength of the mortars containing $10 \%$ mineral admixtures like FA, GS, and SF has registered similar values. The mortars having the same mineral admixtures in the percentage of $20 \%$ have registered a progressive increase from the age of 28 days to the age of 90 days, recording similar values.

As it is well known, the pozzolanic materials form additional calcium silicate hydrate $(\mathrm{C}-\mathrm{S}-\mathrm{H})$ upon the reaction of reactive silica of pozzolan and calcium hydroxide $(\mathrm{CH})$ produced by the cement hydration. This provides additional

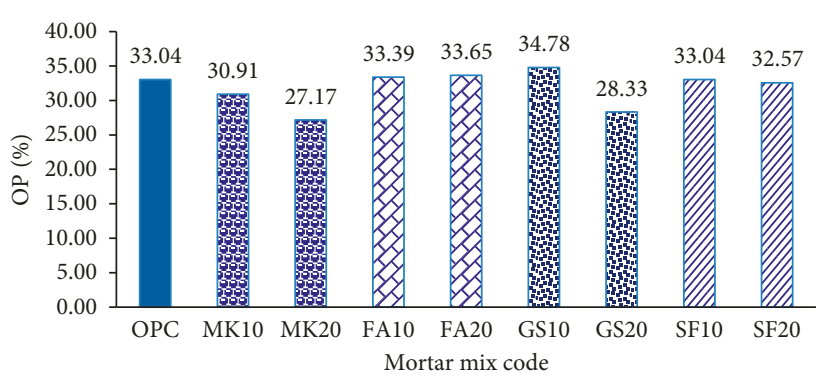

Figure 4: Open porosity, $p(\%)$, of mortars containing SCM, at the age of 28 days.

strength, particularly at later ages. Since sufficient amount of $\mathrm{CH}$ is not available at early ages of hydration of cement, the early strength of pozzolanic mortars can be lower than that of control mortars [43]. This happens with mixture SF 20, which had the lowest early strength.

In regard to the open porosity, $p(\%)$, values are shown in Figure 4. Most of the mineral admixtures that were used did not have a significant influence on the volume of the open pores of mortar. As long as lightweight aggregates were used, it was expected that mortars will present a high volume of open porosity. Thus, it is easy for the water to penetrate into the porous lightweight aggregate [44]. The mortar with metakaolin replacement registered the lowest volume of open porosity, and it was also observed that, by increasing the amount of metakaolin, the volume of pores was decreasing.

The results of the sorptivity test, $S\left(\mathrm{~mm} / \mathrm{min}^{0.5}\right)$, are given in Table 5. The correlation coefficient $\left(R^{2}\right)$ values were found to be near to 1 for all specimens, which satisfies the high degree of linearity that the standard prescribes. The sorptivity values of metakaolin mortar are lower at $10 \%$ cement replacement by metakaolin. Mortars containing silica fume registered approximately the same $S$ values, which shows that the increasing percent of the silica fume content does not affect the sorptivity values. The mortars containing fly ash or ground granulated blast furnace slag registered a lower sorptivity, as the percent of mineral admixture replacement was raised (Figure 5). Elsharief et al. [44] reported that the lightweight aggregate particles themselves contain very large pores as compared with cement paste, but these pores are not continuous and they are sealed off by the dense, surrounding the aggregate, cement paste. 


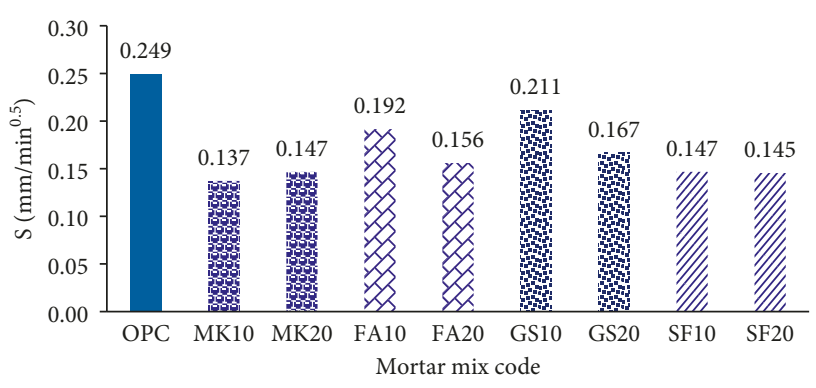

FIGURE 5: Sorptivity, $S\left(\mathrm{~mm} / \mathrm{min}^{0.5}\right)$, of mortars containing SCM, at 28 days.

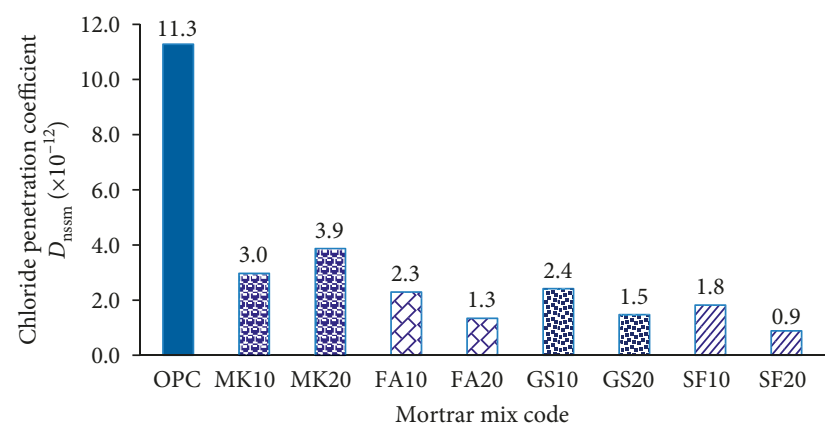

Figure 6: Chloride ion penetration coefficient $D_{\text {nssm }}\left(\times 10^{-12}\right)$ $\left(\mathrm{m}^{2} / \mathrm{s}\right)$ of the mixtures containing SCM.

The resistance to chloride ion penetration is an important aspect that needs a better definition in structural materials. It is generally accepted that mineral admixtures significantly improve it through chloride-binding and porefilling effects [45]. As it can be seen from Table 5, the resistance to chlorides is extremely high and very high in some cases. By adding metakaolin, the results show that protection against chlorides penetration was inferior compared to the addition of the other mineral admixtures. Higher percentage of mineral admixtures ensures a better resistance to chlorides (Figure 6). In this test, the best protection is given by a $20 \%$ cement replacement by silica fume. The pore-filling effect is expected to be the factor that helps in the case of silica fume [45]. However, it must be also noticed that, at high replacement levels of cement by silica fume, the electrical conductivity of the cement paste's pore solution is significantly reduced, since the concentration of $\mathrm{Na}^{+}, \mathrm{K}^{+}$, and $\mathrm{OH}^{-}$of the pore solution is decreased at an order of magnitude, respectively [31].

\section{Conclusions}

Durability tests were performed on lightweight pumice mortars using metakaolin, fly ash, ground granulated blast furnace slag, and silica fume as admixtures. The conclusions of the investigation are summarized below:

(i) The addition of FA and SF at high level of cement replacement in the mortars causes a decrease of the early strength. However, this effect is later reverted, and the compressive strength of mortars containing
FA, SF, GS, and MK is higher than the reference mortar.

(ii) The mineral admixtures used in this experimental program did not have a significant influence on the volume of open pores in mortar, while the usage of MK has shown a better effect; meanwhile, by increasing the percent of metakaolin, the volume of pores decreased.

(iii) Mortars containing SF registered approximately the same percent of absorbed water, which shows that the percent of the SF does not affect the sorptivity. The most efficient mineral admixture regarding the results of the sorptivity test was $\mathrm{MK}$, at an additional level of $10 \%$. Mortar containing SF showed the highest resistance to the chloride penetration. Therefore, higher percentage of mineral admixture such as FA and SF ensures better resistance to chlorides' penetration.

\section{Data Availability}

The raw data of all the conducted tests used to support the findings of this study are available from the corresponding author, upon request.

\section{Conflicts of Interest}

The authors declare that there are no conflicts of interest regarding the publication of this paper.

\section{Acknowledgments}

This research was performed under the frame of Erasmus + HE Traineeship Program, supported by both National Technical Univeristy of Athens and Technical University of Cluj-Napoca.

\section{References}

[1] E. M. Gartner and D. E. Macphee, "A physico-chemical basis for novel cementitious binders," Cement and Concrete Research, vol. 41, no. 7, pp. 736-749, 2011.

[2] A. J. Schokker, The Sustainable Concrete Guide: Strategies and Examples, U.S.: Green Concrete Council, Farmington Hills, MI, USA, 2010.

[3] G. Bumanis, D. Bajare, and A. Korjakins, "Mechanical and thermal properties of lightweight concrete made from expanded glass," Sustainable Architecture and Civil Engineering, vol. 2, no. 3, pp. 26-32, 2013.

[4] H. S. Müller, M. Haist, and A. Hewener, "Self compacting lightweight concrete," Betonwerk und Fertigeil-Technik, vol. 68, pp. 36-39, 2002.

[5] M. Lachemi, S. Bae, K. M. A. Hossain, and M. Sahmaram, "Steel-concrete bond strength on lightweight selfconsolidating concrete," Materials and Structures, vol. 42, no. 7, pp. 1015-1023, 2009.

[6] T. Y. Lo, P. W. C. Tang, H. Z. Cui, and A. Nadeem, "Comparison of workability and mechanical properties of self-compacting lightweight concrete and normal selfcompacting concrete," Materials Research Innovations, vol. 1, no. 1, pp. 45-50, 2007. 
[7] I. B. Topçu and T. Uygunoğlu, "Effect of aggregate type on properties of hardened self consolidating lightweight concrete (SCLC)," Construction and Building Materials, vol. 24, no. 7, pp. 1286-1295, 2010.

[8] T. Uygunoğlu and B. Topçu, "Thermal expansion of selfconsolidating normal and lightweight concrete at elevated temperature," Construction and Building Materials, vol. 23, no. 9, pp. 3063-3069, 2009.

[9] A. Al-Sibany and R. Edwards, "Mechanical and thermal properties of novel lightweight concrete mixtures containing recycled glass and metakaolin," Construction and Building Material, vol. 31, pp. 157-167, 2012.

[10] A. Al-Sibany and R. Edwards, "Thermal behaviour of novel lightweight concrete at ambient and elevated temperatures: experimental, modelling and parametric studies," Construction and Building Materials, vol. 31, pp. 174-187, 2012.

[11] R. Demirboga and R. Gül, "Thermal conductivity and compressive strength of expanded perlite aggregate concrete with mineral admixtures," Energy and Buildings, vol. 32, no. 11, pp. 1155-1159, 2003.

[12] B. Chen and J. Liu, "Experimental application of mineral admixtures in lightweight concrete with high strength and workability," Construction and Building Materials, vol. 22, no. 4, pp. 655-659, 2008.

[13] G. C. Mays and R. A. Barnes, "The performance of lightweight aggregate concrete structures in service," Structural Engineer, vol. 69 , no. 20 , pp. 351-361, 1991.

[14] J. A. Rossignolo and M. V. C Agnesini, "Mechanical properties of polymer-modified lightweight aggregate concrete," Cement and Concrete Research, vol. 32, no. 3, pp. 329-334, 2002.

[15] S. Chandra and L. Berntsson, Lightweight Aggregate Concrete: Science, Technology, and Applications, Noyes Publications, New York, NY, USA, 2002.

[16] E. G. Badogiannis and M. D. Kotsovos, "Monotonic and cyclic flexural tests on lightweight aggregate concrete beams," Earthquake and Structures, vol. 6, no. 3, pp. 317-334, 2014.

[17] M. B. Karakoç, R. Demirboda, I. Turkmen, and I. Can, "Modeling with ANN and effect of pumice aggregate and air entrainment on the freeze-thaw durabilities of HSC," Construction and Building Materials, vol. 25, no. 11, pp. 42414249, 2011.

[18] M. Kurt, S. M. Gul, R. Gul, G. A. Aydin, and T. Kotan, "The effect of pumice powder on the self-compactability of pumice aggregate lightweight concrete," Construction and Building Materials, vol. 103, pp. 36-46, 2016.

[19] L. Gunduz, "The effects of pumice aggregate/cement ratios on the low-strength concrete properties," Construction and Building Materials, vol. 22, no. 5, pp. 721-728, 2008.

[20] İ. Uğur, "Improving the strength characteristics of the pumice aggregate lightweight concretes," in Proceedings of 18th International Mining Congress and Exhibition, pp. 579-585, Madenlerin Gerçek Sahibi Halkımızdır, Antalya, Turkey, April 2003.

[21] E. Badogiannis and S. Tsivilis, "Exploitation of poor Greek kaolins: durability of metakaolin concrete," Cement and Concrete Composites, vol. 31, no. 2, pp. 128-133, 2009.

[22] A. A. Ramezanianpour and H. B. Jovein, "Influence of metakaolin as supplementary cementing material on strength and durability of concretes," Construction and Building Materials, vol. 30, pp. 470-479, 2012.

[23] T. A. Söylev and T. Özturan, "Durability, physical and mechanical properties of fiber-reinforced concretes at low-volume fraction," Construction and Building Materials, vol. 73, pp. 67-75, 2014.

[24] J. A. Bogas and A. Gomes, "Non-steady-state accelerated chloride penetration resistance of structural lightweight aggregate concrete," Cement and Concrete Composites, vol. 60, pp. 111-122, 2015.

[25] E. Badogiannis, I. Sfikas, D. Voukia, and K. Trezos, "Durability of metakaolin self-compacting concrete," Construction and Building Materials, vol. 82, pp. 131-141, 2015.

[26] L. Bokyeong, K. Gyuyong, N. Jeongsoo, C. Bongsuk, H. Yukio, and K. Raehwan, "Compressive strength, resistance to chloride-ion penetration and freezing/thawing of slagreplaced concrete and cementless slag concrete containing desulfurization slag activator," Construction and Building Materials, vol. 128, pp. 341-348, 2016.

[27] P. Van den Heede, M. Maes, and N. De Belie, "Influence of active crack width control on the chloride penetration resistance and global warming potential of slabs made with fly ash and silica fume concrete," Construction and Building Materials, vol. 67, pp. 74-80, 2014.

[28] M. Hale, B. W. Russell, and T. D. Bush, "An assessment of the rapid chloride ion penetrability test," in Proceedings of the International Conference on Concrete for Extreme Conditions, pp. 447-456, University of Dundee, Scotland, UK, 2002.

[29] N. Gowripalan and H. M. Mohamed, "Chloride-ion induced corrosion of galvanized and ordinary steel reinforcement in high-performance concrete," Cement Concrete Research, vol. 28, no. 8, pp. 1119-1131, 1998.

[30] P. E. Streicher and M. G. Alexander, "A critical evaluation of chloride diffusion test methods for concrete," in Proceedings of the Third CANMET/ACI International Conference on Concrete Durability, pp. 517-530, Nice, France, 1994.

[31] C. Shi, J. A. Stegemann, and R. J. Caldwell, "Effect of supplementary cementing materials on the specific conductivity of pore solution and its implications on the rapid chloride permeability test (AASHTO T277 and ASTM C1202) results," ACI Materials Journal, vol. 95, no. 4, pp. 389-394, 1998.

[32] S. J. Möller and P. G. J. Mijnsbergen, "Durability of LWAC made with natural lightweight aggregates," in EuroLightCon: Economic Design and Construction with Light Weight Aggregate Concrete, IceConsult Ltd., Línuhönnun hf., Reykjavík, Iceland, 2000.

[33] R. Polat, R. Demirboğa, M. B. Karakoç, and İ. Türkmen, "The influence of lightweight aggregate on the physico-mechanical properties of concrete exposed to freeze-thaw cycles," Cold Regions Science and Technology, vol. 60, no. 1, pp. 51-56, 2010.

[34] M. S. Choi, J. S. Lee, K. S. Ryu, K. T. Koh, and S. H. Kwon, "Estimation of rheological properties of UHPC using mini slump test," Construction and Building Materials, vol. 106, pp. 632-639, 2016.

[35] ASTM C 642, Standard Test Method for Density, Absorption, and Voids in Hardened Concrete, ASTM International, West Conshohocken, PA, USA, 2013.

[36] C. Hall and T. Kam-Ming Tse, "Water movement in porous building materials-VII. The sorptivity of mortars," Building Environment, vol. 21, no. 2, pp. 113-118, 1986.

[37] RILEM TC 116-PCD, "RILEM technical recommendation: determination of the capillary absorption of water of hardened concrete," Materials and Structures, vol. 32, pp. 178-179, 1999.

[38] NT Build 492, Concrete, Mortar and Cement-Based Materials: Chloride Migration Coefficient from Non-STEADY STATE Migration Experiment, NT Build, Nordtest, Finland, 1999. 
[39] P. R. Spiesz and J. H. Brouwers, "Study on the chloride migration coefficient obtained following different Rapid Chloride Migration (RCM) test guidelines," in Proceedings of International Conference on Advances in Cement and Concrete Technology (ACCTA), BAM Federal Institute for Materials, pp. 923-930, Johannesburg, South African, 2013.

[40] K. D. Stanish, R. D. Hooton, and M. D. A. Thomas, "Testing the chloride penetration resistance of concrete: a literature review," in FHWA Contract DTFH61-97-R-00022, Department of Civil Engineering, University of Toronto, Toronto, ON, Canada, 1997.

[41] H. S. Kim, S. H. Lee, and H. Y. Moon, "Strength properties and durability aspects of high strength concrete using Korean metakaolin," Construction and Building Materials, vol. 21, no. 7, pp. 1229-1237, 2007.

[42] N. Otsuki, S. Nagataki, and K. Nakashita, "Evaluation of the $\mathrm{AgNO}_{3}$ solution spray method for measurement of chloride penetration into hardened cementitious matrix materials," Construction and Building Materials, vol. 7, no. 4, pp. 195-201, 1993.

[43] A. Mardani-Aghabaglou, E. Yogurtcu, and Ö. Andiç-Çakır, "Water transport of lightweight concrete with different aggregate saturation levels," ACI Materials Journal, vol. 112, no. 5, pp. 681-691, 2015.

[44] A. Elsharief, D. M. Cohen, and J. Olek, "Influence of lightweight aggregate on the microstructure and durability of mortar," Cement and Concrete Research, vol. 35, no. 7, pp. 1368-1376, 2005.

[45] K. G. Babu and D. S. Babu, "Behaviour of lightweight expanded polystyrene concrete containing silica fume," Cement and Concrete Research, vol. 33, no. 5, pp. 755-762, 2003. 


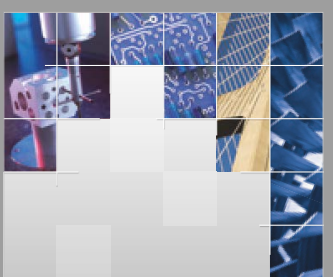

\section{Enfincering}
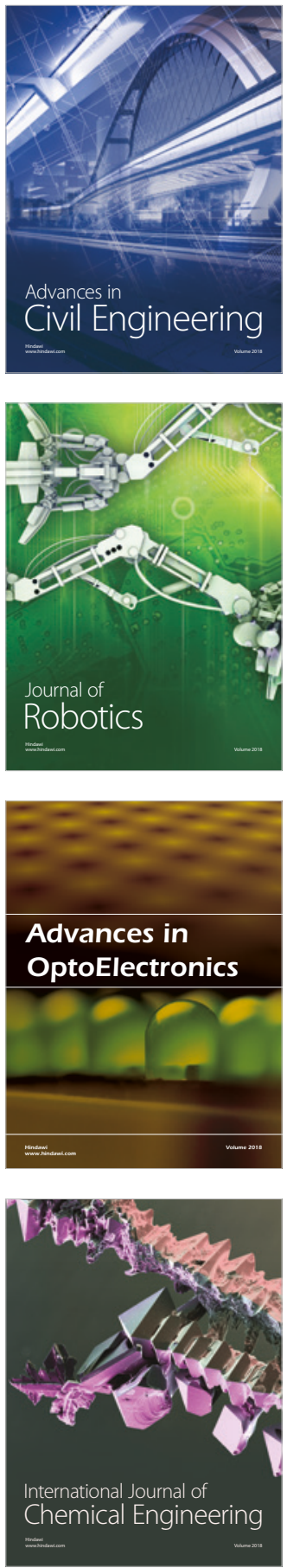

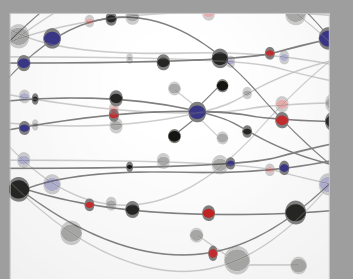

\section{Rotating \\ Machinery}

The Scientific World Journal

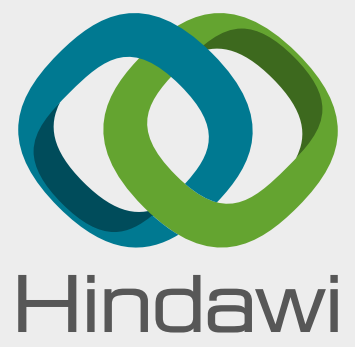

Submit your manuscripts at

www.hindawi.com
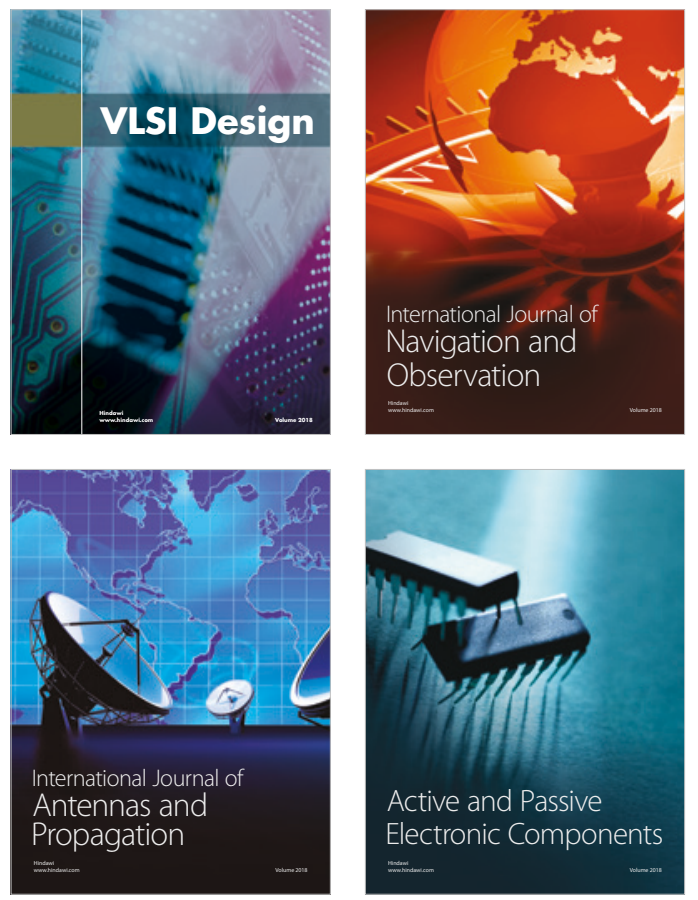
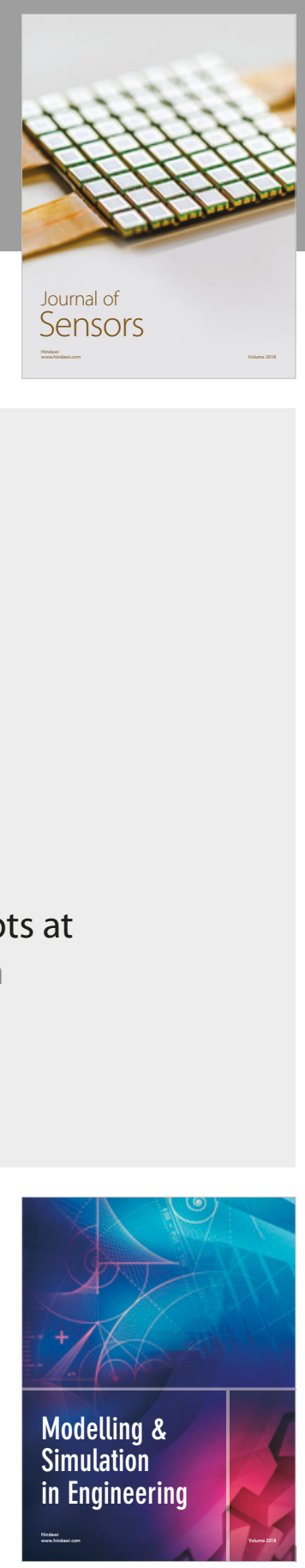

\section{Advances \\ Multimedia}
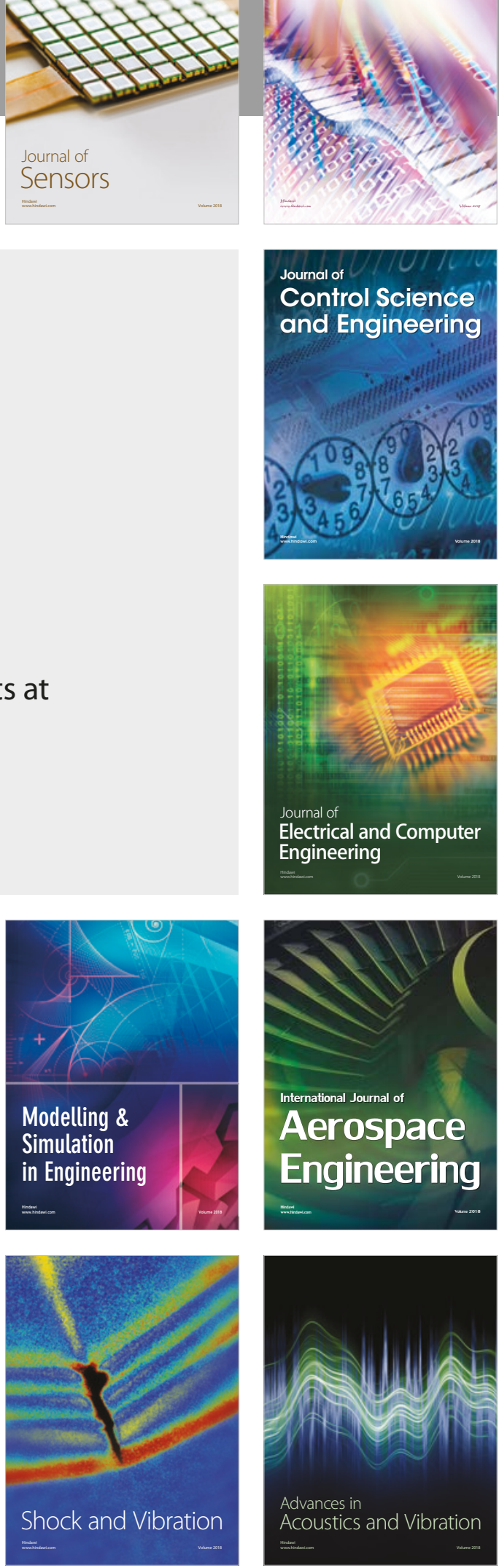